University of Wollongong

Research Online

Faculty of Engineering and Information

Faculty of Engineering and Information

Sciences - Papers: Part B

Sciences

2018

Physics-based Constitutive Model for the Hot Deformation of 2Cr11Mo1VNbN Martensitic Stainless Steel

Rui Wang

University of Wollongong, rw985@uowmail.edu.au

Menghan Wang

Chongqing University

Zhi Li

Chongqing University

Cheng Lu

University of Wollongong, chenglu@uow.edu.au

Follow this and additional works at: https://ro.uow.edu.au/eispapers1

Part of the Engineering Commons, and the Science and Technology Studies Commons

Research Online is the open access institutional repository for the University of Wollongong. For further information contact the UOW Library: research-pubs@uow.edu.au 


\title{
Physics-based Constitutive Model for the Hot Deformation of 2Cr11Mo1VNbN Martensitic Stainless Steel
}

\author{
Abstract \\ The hot deformation behavior of $2 \mathrm{Cr} 11 \mathrm{Mo} 1 \mathrm{VNbN}$ martensitic stainless steel is investigated through \\ isothermal compression tests between 1173 and $1423 \mathrm{~K}$ with strain rates of $0.005-5 \mathrm{~s}^{-1}$. Based on \\ experimental results, the work hardening-dynamic recovery stage and dynamic softening stage are \\ evaluated, and a couple-stage constitutive model is developed to describe the work hardening-dynamic \\ recovery and dynamic softening behaviors. Phenomenological constitutive models, which consider \\ temperature, strain and strain rate, are established. A comparison between the predicted and \\ experimental flow stress values indicates that the established models accurately describe the hot \\ deformation behaviors for the studied supercritical steel. \\ Disciplines \\ Engineering | Science and Technology Studies \\ Publication Details \\ Wang, R., Wang, M., Li, Z. \& Lu, C. (2018). Physics-based Constitutive Model for the Hot Deformation of \\ $2 \mathrm{Cr} 11 \mathrm{Mo} 1 \mathrm{VNbN}$ Martensitic Stainless Steel. Journal of Materials Engineering and Performance, 27 (9), \\ 4932-4940.
}




\title{
Physically-based constitutive model of hot deformation for 2Cr11Mo1VNbN martensitic stainless steel
}

\author{
Rui Wang ${ }^{\mathrm{a}}$, Menghan Wang ${ }^{\mathrm{b}}$, Zhi Li ${ }^{\mathrm{b}}$, Cheng $\mathrm{Lu}^{\mathrm{a}}$ \\ a School of Mechanical, Materials, Mechatronic and Biomedical Engineering, University of \\ Wollongong, Wollongong, NSW 2522, Australia \\ ${ }^{\mathrm{b}}$ School of Material Science and Engineering, Chongqing University, Chongqing 400044, China
}

\begin{abstract}
:
The hot deformation behavior of $2 \mathrm{Cr} 11 \mathrm{Mo} 1 \mathrm{VNbN}$ martensitic stainless steel is investigated through isothermal compression tests between $1173 \mathrm{~K}$ and $1423 \mathrm{~K}$ with strain rates of $0.005-5 \mathrm{~s}^{-1}$. Based on the experimental results, the work hardening-dynamic recovery stage and dynamic softening stage are evaluated, and a couple-stage constitutive model is developed to describe the work hardening-dynamic recovery behavior and dynamic softening behavior. The phenomenological constitutive models, which take the temperature, strain and strain rate into account, are established. Comparison between the predicted and experimental flow stress indicated that the established models accurately describe the hot deformation behaviors for the studied supercritical steel.
\end{abstract}

\section{Key words:}

Hot deformation; Dynamic recrystallization; Work hardening; Dynamic recovery; Constitutive modelling

\section{Introduction}

Martensitic stainless steels are widely used in critical parts of industrial equipment, such as surgical instruments, steam turbines and nuclear power equipment. The alloying elements in the steel make it with high strength and corrosion resistance. However, the formability at room temperature of the steel limits its application in the 
field of engineering. Manufacturing process of the steel usually conducted at elevated temperatures to get preferable formability. A constitutive model of materials depicts flow behavior of the material, providing an important tool for investigating the hot deformation behavior in finite element simulation (Ref 1). The accuracy of finite element simulation mainly depends on exactitude of constitutive model of the material. Accurate constitutive models are required to depict the hot deformation behaviors of materials. The hot deformation behaviors of metals are complex and nonlinear relationships of flow stress, strain, strain rate and temperature, due to the complex deformation mechanisms, including work hardening (WH), dynamic recovery (DRV) and dynamic recrystallization (DRX).

During hot working conditions, WH, DRV and DRX behaviors often occur in metals or alloys with low stacking fault energy (Ref 2-4). Generally, the WH and DRV behavors in materials can be well explained by dislocation density theory (Ref $5,6)$. In plastic deformation, the accumulation of dislocations leads to $\mathrm{WH}$, while the annihilation of dislocations leads to a reduction of dislocation density, resulting in decrease of flow stress. During hot deformation, microstructure evolution and internal defects development contribute to the softening process (Ref 7-11). Both hardening and softening behaviors are affected by the hot deformation parameters. DRX behavior is an important element in microstructural evolution of materials and is mainly influenced by the deformation conditions and original microstructure (Ref 12 , 13). Similar to DRX, the heating during deformation can also result in a drop in flow stress and cause thermal softening (Ref 14). In recent years, many studies have been conducted to explore hot deformation behavior of materials. Lin et al. presented multi-gene genetic programming (MGGP), artificial neural network (ANN) and Arrhenius type phenomenological models predict the flow stress of a nickel-based superalloy (Ref 15). Nima et al. modeled the hot compression behavior of the studied material with a modified Estrin-Mecking approach (Ref 16). Mandal et. al. proposed a constitutive equation to predict high temperature flow stress in a Ti-modified austenitic stainless steel (Ref 17). Gupta et al. studied the constitutive model to predict the flow stress of 316 austenitic stainless steel (Ref 18). Momeni and 
Dehghani analyzed the relationship between the flow stress and Zener-Hollomon parameter and developed the power dissipation and the instability map of AISI 410 martensitic stainless steel (Ref 19). Ren et. al. proposed a constitutive model to describe the hot deformation behavior of X20Cr13 martensitic stainless steel with strain effect (Ref 20). Mohseni developed a two-stage model to predict the plastic flow stress via an extended Ludwik model at low temperatures and a Zener-Hollomon model at high temperatures (Ref 21). Zeng et al. studied the peak strain and kinetic equation for DRX of $403 \mathrm{~b}$ heat-resistant martensitic stainless steel (Ref 22). Abbasi-Bani et. al. analyzed the capability of Johnson-Cook and Arrhenius-type constitutive equations to describe the flow behavior of an Mg-6Al-1Zn alloy (Ref 23). Li et. al. proposed a comparative study on modified Johnson Cook, modified Zerilli-Armstrong and Arrhenius-type constitutive models to predict the hot deformation behavior of $28 \mathrm{CrMnMoV}$ steel (Ref 24). Ravindranadh established constitutive models of high-strength armor steel using the original Johnson-Cook (JC) model, modified JC model, and strain-compensated Arrhenius model (Ref 25). However, it can be noticed that these models do not consider the physical deformation mechanisms, such as WH, DRV and DRX behavior in deformation. The aim of this work is to characterize the hot deformation behavior of studied steel by isothermal compression tests under different deformation conditions, and establish a physically-based constitutive model considering the WH-DRV and DRX mechanisms to depict the hot deformation behavior. A statistical comparison was performed to validate the predicting capability.

\section{Materials and Experiments}

Commercially available forged martensitic stainless steel with the chemical composition (wt.\%) of $0.183 \mathrm{C}, 0.38 \mathrm{Si}, 0.68 \mathrm{Mn}, 0.014 \mathrm{P}, 0.010 \mathrm{~S}, 0.48 \mathrm{Ni}, 10.48 \mathrm{Cr}$, $0.87 \mathrm{Mo}, 0.09 \mathrm{Nb}, 0.20 \mathrm{~V}, 0.076 \mathrm{~N}$, and remainder Fe. is used in this study. Cylindrical specimens with a diameter of $8 \mathrm{~mm}$ and a height of $12 \mathrm{~mm}$ were prepared by wire-electrode cutting. Hot compression tests were performed using a Gleeble-3500 
thermo-mechanical test simulator. The tests were conducted at the temperatures range from $1173 \mathrm{~K}$ to $1423 \mathrm{~K}$ with the strain rate of $0.005 \mathrm{~s}^{-1}, 0.05 \mathrm{~s}^{-1}, 0.5 \mathrm{~s}^{-1}, 5 \mathrm{~s}^{-1}$. Compression tests were carried out in an inert atmosphere and samples were equipped with type S thermocouples. All samples were heated to $1473 \mathrm{~K}$ at a heating rate of $10 \mathrm{~K} / \mathrm{s}$ and held for 3 minutes to obtain uniform microstructure. The specimens were cooled to the corresponding deformation temperatures at cooling rate of $20 \mathrm{~K} / \mathrm{s}$ and held for 2 minutes to ensure a uniform material temperature. The detailed deformation processing path is shown in Fig. 1(b). Tantalum foil of $0.1 \mathrm{~mm}$ thickness and graphite lubricant were used between the specimen and dies to reduce friction. The specimens were then quenched in water after compression tests. The stress-strain data were automatically recorded by the testing system. In order to observe the microstructure, specimens were chemically etched with $33 \% \mathrm{HNO}_{3}+33 \%$ acetic acid $+33 \% \mathrm{H}_{2} \mathrm{O}+1 \%$ HF to reveal the grain boundaries. The original optical microstructure of the hot compression test samples is shown in Fig. 1(a), and the mean initial average grain size of the materials is $158 \mu \mathrm{m}$ by planimetric procedure (ASTM:E112-13).

\section{Experimental results and analysis}

\subsection{Flow stress behavior and microstructure}

The experimental stress-strain curves under various deformation conditions are presented in Fig. 2. It can be found from the figure that the stress significantly increases to a peak with the increase of strain at initial stage, due to dislocations generation and multiplication induced by work hardening. At this stage, the work hardening caused by dislocations is dominant and powerful rather than the compensation of softening of DRV (Ref 26). With increasing strain, the flow stress will decreases due to compensation of softening becomes more powerful that work hardening effects can be partially countervailed by softening mechanisms like DRV and DRX. Finally, an equilibrium will be achieve between work hardening effects caused by dislocations multiplication and softening effects caused by dislocations 
annihilation. In microstructural scale, microstructure evolution during hot deformation process is consider as an equilibrium between WH and softening. The peak stress increases significantly with increasing strain rate and decreasing temperature. The curves at temperature above $1273 \mathrm{~K}$ with a strain rate below $0.05 \mathrm{~s}^{-1}$ exhibit a flow stress curve with a single peak and achieve the steady state condition. The steady condition is not achieved at temperatures below $1273 \mathrm{~K}$ and strain rate above $0.05 \mathrm{~s}^{-1}$. The peaks observed in the curves indicates the appearance of DRX at temperatures greater than $1273 \mathrm{~K}$ and strain rates below $0.05 \mathrm{~s}^{-1}$, while the unobvious peaks and steady states signifies the incomplete DRX due to the limited strain of 0.7 (Ref 27). In this steel, the flow stress curves obtained at low strain rate show weak softening followed by steady state of flow stress while at high strain rates distinct softening characteristics is observed. This phenomena is mainly attributed to adiabatic heating effects that generated heat cannot effective dissipated in short time. At low strain rates, the long deformation time enhances the softening effects of DRV and DRX resulting in lower flow stress. In the deformation process, higher temperatures provide a larger driving force for dislocation annihilation and grain boundary migration, which results in recovery and recrystallization (Ref 28,29$)$.

Fig. 3 shows the optical microstructure of the tested specimens at strain of 0.7 under different deformation temperatures and strain rates. Compared with Fig. 1(a), nearly all coarse original grains in Fig. 3 are replaced by the new grains, and grains maintain equiaxed shapes and constant sizes. At the strain of 0.7 , the recrystallization nearly complete and the microstructure become much more homogeneous. The average grain sizes were measured as (a) $38 \mu \mathrm{m}$, (b) $51 \mu \mathrm{m}$, (c) $97 \mu \mathrm{m}$, (d) $83 \mu \mathrm{m}$ for the different deformation conditions. It can been seen that the grain size increased accompanied by increase of temperature (Fig. 3(a,b)) and decrease of strain rate (Fig.3(c,d)). The phenomenon is mainly attributed to dislocation multiplication and annihilation: high temperature increases the dislocation annihilation and grain boundary migration, which lead grains to grow up, and high strain rate contributes to work hardening and results in insufficient time for recrystallization and grow up of the grains. In hot deformation process, the nucleation of DRX is promoted by large 
stored energy while the grain growth is enhanced by drying force of heating and long deformation period. The terminal grain size is dependent on the synergistic effects of deformation rate, stored energy and adiabatic heating.

\subsection{Work hardening and dynamic recovery}

The dislocation storage and annihilation contribute to dislocation density and result in DRV and DRX during hot deformation. The dislocation evolution can be expressed as $(\operatorname{Ref} 21)$,

$d \rho / \mathrm{d} \varepsilon=U-\Omega \rho$

where $U, \Omega$ and $\rho$ represent dislocation multiplication, the annihilation coefficient and dislocation density, respectively. $\Omega \rho$ represents the DRV due to the dislocation annihilation and rearrangement. Integrating Eq. (1), the $\rho$ can be expressed as,

$\rho=\rho_{0} e^{-\Omega \varepsilon}+\left(\frac{U}{\Omega}\right)\left(1-e^{-\Omega \varepsilon}\right)$

where $\rho_{0}$ is the initial dislocation density. Previous studies have shown that at high temperatures, the effective stress is negligible compared to the internal stress (Ref 30 , 31), so that the applied stress can be related directly to the square root of the dislocation density,

$\sigma=\alpha \mu b \sqrt{\rho}$

where $\alpha$ is the material constant, $\mu$ is the shear modulus, $b$ is the distance between atoms along slip direction. Combining the equations above, the flow stress during WH and DRV period can be expressed as (Ref $30,32,33)$,

$\sigma=\left[\sigma_{\text {sat }}^{2}+\left(\sigma_{0}^{2}-\sigma_{\text {sat }}^{2}\right) e^{-\Omega \varepsilon}\right]^{0.5}$

o r $\quad \sigma=\left[\sigma_{0}^{2} e^{-\Omega \varepsilon}+(\alpha \mu b)^{2}\left(\frac{U}{\Omega}\right)\left(1-e^{-\Omega \varepsilon}\right)\right]^{0.5}$

where $\sigma$ is the flow stress. The saturation stress $\sigma_{\text {sat }}$ and yield stress $\sigma_{0}$ are equal to $\alpha \mu b \sqrt{U / \Omega}$ and $\alpha \mu b \sqrt{\rho}$, respectively.

To determine the constitutive equation in Eq. (4), the parameters of saturation 
stress $\left(\sigma_{\text {sat }}\right)$, yield stress $\left(\sigma_{0}\right)$, and DRV coefficient $(\Omega)$ need to be calculated.

Fig. 4 illustrates the work hardening curves of the studied steel at different temperatures and strain rates. Regimes, where the curve sharply decreases, are defined as before the DRX onset. The inflections in working-hardening curves, DRX critical point correspondingly, have been demonstrates as transformation between two competition mechanisms. Fig. 5 shows the relationship between the work hardening rate $(\theta)$ and flow stress $(\sigma)$ at $1373 \mathrm{~K}$ with strain rate of $5 \mathrm{~s}^{-1}$. The curves show that the work hardening rate decreases dramatically with an increase in flow stress due to potential early stage DRV behavior. In regimes II, a less severe slope can be observed, indicating DRX. The inflection point can be determined by the peak value of $(\partial \theta / \partial \sigma)$. The inflection point in the $\theta-\sigma$ curves in Fig. 4 is determined by the peak point in the $(\partial \theta / \partial \sigma)$ versus $\sigma$ curve, which corresponds to the initiation of DRX, according to the method of Poliak and Jonas (Ref 34).

Saturation stress $\sigma_{\text {sat }}$ cannot express the stress directly, though it can be expressed as the function of peak stress $\sigma_{p}$. The relationship between the saturation stress and peak stress is shown in Fig. 6. These properties have a linear relationship that can be expressed as follows,

$\sigma_{\text {sat }}=0.0195+1.02 \sigma_{p}$

In general, the combined effects of forming temperature and strain rate on the flow stress can be expressed by the Zener-Hollomon parameter as follows (Ref 35),

$Z=\dot{\varepsilon} \exp (Q / R T)$

where $\dot{\varepsilon}$ is the strain rate, $R$ is the universal gas constant $\left(8.314 \mathrm{~J} \cdot \mathrm{mol}^{-1} \cdot \mathrm{K}^{-1}\right)$, T is the absolute temperature $(\mathrm{K}) \cdot Q$ is the activation energy $\left(\mathrm{J} \cdot \mathrm{mol}^{-1}\right)$ and is calculated to be $509.71 \mathrm{k} \mathrm{J} \cdot \mathrm{mol}^{-1}$.

The yield stress $\sigma_{0}$ over a range of deformation temperatures and strain rates can be obtained from the flow stress-strain curves. The relationship between the yield stress and $Z$ parameter is shown in Fig. 7, and the linear relationship can be expressed as, 
According to Eq. (4) the DRV coefficient $\Omega$ can be described as,

$\Omega=\frac{1}{\varepsilon} \ln \left(\frac{\sigma_{\text {sat }}^{2}-\sigma_{0}^{2}}{\sigma_{\text {sat }}^{2}-\sigma^{2}}\right)$

The coefficient $\Omega$ can be determined based on the flow stress-strain curves, and can be expressed by $Z$ parameter (Fig. 8),

$\Omega=42.1 Z^{-0.0262}$

Based on the equations above, the flow stress equations of WH-DRV period of the steel can be described as,

$$
\left\{\begin{array}{l}
\sigma=\left[\sigma_{\text {sat }}^{2}+\left(\sigma_{0}^{2}-\sigma_{\text {sat }}^{2}\right) e^{-\Omega \varepsilon}\right]^{0.5} \quad\left(\varepsilon<\varepsilon_{c}\right) \\
\sigma_{\text {sat }}=0.0195+1.02 \sigma_{p} \\
\sigma_{0}=2.03 \ln Z-56.2 \\
\Omega=42.1 Z^{-0.0262} \\
Z=\dot{\varepsilon} \exp \left(5.10 \times 10^{5} / R T\right)
\end{array}\right.
$$

To determine if DRX has occurred, the critical strain $\varepsilon_{c}$ is associated with the peak strain and expressed by the dimensionless parameter $Z / A$ (Ref 16,36). The linear fitting of the critical strain, critical stress, peak strain and peak stress with the dimensionless parameter $Z / A$ are shown in Fig. 9. The relationships can be expressed as,

$\left\{\begin{array}{c}\sigma_{c}=0.504 Z^{0.120} \\ \varepsilon_{c}=0.0240 Z^{0.0417} \\ \sigma_{p}=0.565 Z^{0.120} \\ \varepsilon_{p}=0.0902 Z^{0.0252}\end{array}\right.$

\subsection{Kinetics of DRX}

In this investigation, the Avrami type equation (Ref $37-40)$ is used to describe the DRX behavior,

$X_{d}=1-\exp \left[(-k)\left(\frac{\varepsilon-\varepsilon_{c}}{\varepsilon_{p}}\right)^{n}\right]$

where $X_{d}$ is the volume fraction of DRX; $k, n$ are the material constants; $\varepsilon, \varepsilon_{p}$ and $\varepsilon_{c}$ 
are the true strain, peak strain and critical strain, respectively. Meanwhile, the flow stress is also related to the evolution of microstructures. Based on the Avrami equation, the recrystallization volume fraction $X_{d}$ can be determined as (Ref 16, 38),

$X_{d}=\frac{\sigma_{\mathrm{DRV}}-\sigma}{\sigma_{s a t}-\sigma_{s s}}$

where $\sigma$ is the instantaneous flow stress, and $\sigma_{\text {sat }}$ and $\sigma_{s s}$ are the saturated stress and steady state stress, respectively.

Based on Eq. (13) and (14), the flow stress in DRX stage can be expressed as,

$\sigma=\sigma_{D R V}-\left(\sigma_{s a t}-\sigma_{s S}\right)\left\{1-\exp \left[-k\left(\frac{\varepsilon-\varepsilon_{c}}{\varepsilon_{p}}\right)^{n}\right]\right\} \quad\left(\varepsilon \geq \varepsilon_{c}\right)$

Taking the natural logarithm on both sides of Eq. (15), Eq. (15) can be expressed as Eq. (16),

$\ln \ln \left(\frac{1}{1-X_{d}}\right)=\ln k+n \ln \left(\frac{\varepsilon-\varepsilon_{c}}{\varepsilon_{p}}\right)$

The value of $k$ and $n$ can be determined by linear fitting in combination with the volume fraction of DRX and Eq. (16). The linear relationship between $\ln \ln \left(1 /\left(1-X_{d}\right)\right)$ and $\ln \left(\left(\varepsilon-\varepsilon_{c}\right) / \varepsilon_{p}\right)$ is shown in Fig. 10. The slope value of the regression fitting line is $n$, and the intercept of the fitting line is $l n k$. Therefore, the kinetic model of DRX can be described as,

$X_{d}=1-\exp \left[(-0.923)\left(\frac{\varepsilon-\varepsilon_{c}}{\varepsilon_{p}}\right)^{1.52}\right]$

On the basis of Eq. (17), the effects of deformation temperature, strain and strain rate on the DRX volume fraction are shown in Fig. 11. The deformation strain required for the same volume DRX fraction increases with increasing strain rate and decreases with increasing temperature.

Fig. 12 shows the dependence of the steady stress $\sigma_{\mathrm{ss}}$ on the peak stress $\sigma_{p}$, and the relationship can be described as,

$\sigma_{s s}=0.988 \sigma_{p}$ 
Therefore, the constitutive equations during the WH, DRV and DRX periods of the steel can be expressed as,

$$
\left\{\begin{array}{c}
\sigma=\left[\sigma_{\text {sat }}^{2}+\left(\sigma_{0}^{2}-\sigma_{\text {sat }}^{2}\right) e^{-\Omega \varepsilon}\right]^{0.5} \quad\left(\varepsilon<\varepsilon_{c}\right) \\
\sigma=\sigma_{D R V}-\left(\sigma_{\text {sat }}-\sigma_{s S}\right)\left\{1-\exp \left[-k\left(\frac{\varepsilon-\varepsilon_{c}}{\varepsilon_{p}}\right)^{n}\right]\right\} \quad\left(\varepsilon \geq \varepsilon_{c}\right) \\
\sigma_{p}=\frac{1}{0.00785} \ln \left\{\left(\frac{Z}{1.0 \times 10^{19}}\right)^{\frac{1}{5.9925}}+\left[\left(\frac{Z}{1.0 \times 10^{19}}\right)^{\frac{1}{5.9925}}+1\right]^{\frac{1}{2}}\right\} \\
\sigma_{\text {sat }}=1.02 \sigma_{p}+0.0195 \\
\sigma_{0}=2.03 \ln Z-56.2 \\
Z=\dot{\varepsilon} \exp \left(5.10 \times 10^{5} / R T\right) \\
\Omega=42.1 Z^{-0.0262} \\
\sigma_{s S}=0.988 \sigma_{p} \\
\varepsilon_{c}=0.0240 Z^{0.0417} \\
\varepsilon_{p}=0.0902 Z^{0.0252}
\end{array}\right.
$$

\subsection{Verification of developed constitutive model}

To verify prediction accuracy of the developed constitutive model, comparison between the experimental and predicted flow stress data is shown in Fig. 13. These results show that the predictions are in good agreement with the experimental data.

The predictability of the constitutive equations considering strain compensation can be described through the correlation coefficient $(R)$ and the average absolute relative error $(A A R E)$, which can be defined as,

$$
\begin{aligned}
& R=\frac{\sum_{i=1}^{N}\left(E_{i}-\bar{E}\right)\left(P_{i}-\bar{P}\right)}{\sqrt{\sum_{i=1}^{N}\left(E_{i}-\bar{E}\right)^{2} \sum_{i=1}^{N}\left(P_{i}-\bar{P}\right)^{2}}} \\
& \operatorname{AARE}(\%)=\frac{1}{N} \sum_{i=1}^{N}\left|\frac{E_{i}-P_{i}}{E_{i}}\right| \times 100
\end{aligned}
$$

The correlation between experimental data and predicted data over the entire range of strain, strain rate and temperature is shown in Fig. 14. The calculated correlation coefficients and average absolute relative errors are 0.998 and $2.34 \%$, indicating the newly established models can be used to predict the flow stresses of the studied martensitic stainless steel. 


\section{Conclusions}

In this paper, the hot behavior of the $2 \mathrm{Cr} 11 \mathrm{Mo} 1 \mathrm{VNbN}$ martensitic stainless steel is investigated over a temperature range of 1173-1423 $\mathrm{K}$ and stain rate range of $0.005-5 \mathrm{~s}^{-1}$. Based on the experimental data, a physically-based constitutive models were established to describe the hot deformation behaviors (WH, DRV and dynamic softening behavior) of the studied steel. The physically-based equations developed could be used to describe the WH-DRV period and DRX period and thus improve the reliability of flow behavior. The comparison between the measured and predicted results indicates that the proposed constitutive equations can accurately characterize the flow behavior and used in numerical simulation of the hot deformation process of the studied steel.

\section{Acknowledgement}

The authors appreciate the financial supports from the Fundamental Research Funds for the Central Universities [grant number CDJZR14130006].

\section{Reference}

1. V. Vilamosa, A.H. Clausen, T. Børvik, B. Holmedal, O.S. Hopperstad. A physically-based constitutive model applied to AA6082 aluminium alloy at large strains, high strain rates and elevated temperatures, Mater. Des. 2016, 103, p 391405.

2. A. Momeni, K. Dehghani, G. R. Ebrahimi. Modeling the initiation of dynamic recrystallization using a dynamic recovery model, J. Alloys Compd., 2011, 509, p 9387-9393.

3. E. Farabi, A. Zarei-Hanzaki, H.R. Abedi, High temperature formability prediction of dual phase brass using phenomenological and physical constitutive models, J. Mater. Eng. Perform, 2015, 24, p 209-220.

4. B. Thossatheppitak, V. Uthaisangsuk, P. Mungsuntisuk, S. Suranuntchai, A. 
Manonukul. Flow behavior of Nickel Aluminium Bronze under hot deformation, Mater. Sci. Eng. A, 2014, 604, p 183-190.

5. Y. C. Lin, D. X. Wen, M. S. Chen, Y. X. Liu, X. M. Chen, X. Ma. Improved dislocation density based models for describing hot deformation behaviors of a Ni-based superalloy. J. Mater. Res., 2016, 31, p 2415 - 2429.

6. Y. Estrin, H. Mecking. A unified phenomenological description of work hardening and creep based on one-parameter models. Acta Metall., 1984, 32, p 57-70.

7. J. Q. Zhang, H. S. Di, X. Y. Wang. Flow softening of 253MA austenitic stainless steel during hot compression at higher strain rates, Mater. Sci. Eng. A, 2016, 650, p 483-491.

8. P. Cizek. The microstructure evolution and softening processes during high-temperature deformation of a $21 \mathrm{Cr}-10 \mathrm{Ni}-3 \mathrm{Mo}$ duplex stainless steel, Acta Mater., 2016, 106, p 129-143.

9. K. K. Li, M. S. Chen, Y.C. Lin, W. Q. Yuan. Microstructural evolution of an aged Ni-based superalloy under two-stage hot compression with different strain rates, Mater. Des., 2016, 111, p 344-352.

10. S. S. S. Kumar, T. Raghu, Pinaki P. Bhattacharjee, G. A. Rao, U. Borah. Constitutive modeling for predicting peak stress characteristics during hot deformation of hot isostatically processed nickel-base superalloy, J. Mater. Sci., 2015, 50, p 6444-6456.

11. S. L. Semiatin, J. J. Jonas, Formability and workability of metals, plastic instability and flow localization. Ohio: American Society for Metals, Metals Park, 1984.

12. K. Graetz, C. Miessen, G. Gottstein. Analysis of steady-state dynamic recrystallization, Acta. Mater., 2014, 67, p 58-66.

13. A. Galiyev, R. Kaibyshev, G. Gottstein. Correlation of plastic deformation and dynamic recrystallization in magnesium alloy ZK60, Acta. Mater., 2001, 49, p 1199-1207.

14. J. Q. Zhang, H. S. Di, H. T. Wang, K. Mao, T. J. Ma, Y. Cao. Hot deformation behavior of Ti-15-3 titanium alloy: A study using processing maps, activation 
energy map, and Zener-Hollomon parameter map, J. Mater. Sci., 2012, 47, p 4000-4011.

15. Y. C. Lin, F. Q. Nong, X. M. Chen, D. D. Chen, M. S. Chen. Microstructural evolution and constitutive models to predict hot deformation behaviors of a nickel-based superalloy. Vacuum, 2017, 137, p 104-114.

16. N. Haghdadi, D. Martin, P. Hodgson. Physically-based constitutive modelling of hot deformation behavior in a LDX 2101 duplex stainless steel, Mater. Des., 2016, 106, p 420-427.

17. S. Mandal, V. Rakesh, P. V. Sivaprasad, S. Venugopal, K. V. Kasiviswanathan. Constitutive equations to predict high temperature flow stress in a Ti-modified austenitic stainless steel, Mater. Sci. Eng. A, 2009, 500, p 114-121.

18. A. K. Guptaa, V. K. Anirudh, S. K. Singh. Constitutive models to predict flow stress in Austenitic Stainless Steel 316 at elevated temperatures, Mater. Des., 2013, 43, p 410-418.

19. A. Momeni, K. Dehghani. Characterization of hot deformation behavior of 410 martensitic stainless steel using constitutive equations and processing maps, Mater. Sci. Eng. A, 2010, 527, p 5467-5473.

20. F. Ren, J. Chen, F. Chen. Constitutive modeling of hot deformation behavior of X20Cr13 martensitic stainless steel with strain effect, Trans. Nonferr. Metal. Soc. 2014, 24, p 1407-1413.

21. S. M. Mohseni, A. B. Phillion, D. M. Maijer. Modelling the constitutive behaviour of aluminium alloy B206 in the as-cast and artificially aged states. Mater. Sci. Eng. A, 2016, 649, p 382-389.

22. Z. Y. Zeng, L. Q. Chen, F. X. Zhu, X. H. Liu. Dynamic recrystallization behavior of a heat-resistant martensitic stainless steel $403 \mathrm{Nb}$ during hot deformation, $\mathrm{J}$. Mater. Sci. Technol., 2011, 27, p 913-919.

23. A. Abbasi-Bani, A. Zarei-Hanzaki, M. H. Pishbin, N. Haghdadi. A comparative study on the capability of Johnson-Cook and Arrhenius-type constitutive equations to describe the flow behavior of $\mathrm{Mg}-6 \mathrm{Al}-1 \mathrm{Zn}$ alloy, Mech. Mater., 2014, 71, p 52-61. 
24. H. Y. Li, Y. H. Li, X. F. Wang, J. J. Liu, Y. Wu. A comparative study on modified Johnson Cook, modified Zerilli-Armstrong and Arrhenius-type constitutive models to predict the hot deformation behavior in $28 \mathrm{CrMnMoV}$ steel, Mater. Des., 2013, 49, p 493-501.

25. R. Bobbili, V. Madhu. Constitutive modeling of hot deformation behavior of high-strength armor steel, J. Mater. Eng. Perform., 2016, 25, p 1829-1838.

26. S. S. S. Kumar, T. Raghu, P. P. Bhattacharjee, G. A. Rao, U. Borah. Strain rate dependent microstructural evolution during hot deformation of a hot isostatically processed nickel base superalloy. J. Alloys Compd., 2016, 681, p 28-42

27. Q. C. Fan, X. Q. Jiang, Z. H. Zhou, W. Ji, H. Q. Cao. Constitutive relationship and hot deformation behavior of Armco-type pure iron for a wide range of temperature, Mater. Des., 2015, 65, p 193-203.

28. A. Hajari, M. Morakabati, S. M. Abbasi, H. Badri. Constitutive modeling for high-temperature flow behavior of Ti-6242S alloy, Mater. Sci. Eng. A, 2017, 681, p 103-113.

29. X. M. Chen, Y.C. Lin, D. X. Wen, J. L. Zhang, M. He. Dynamic recrystallization behavior of a typical nickel-based superalloy during hot deformation, Mater. Des., 2014, 57, p 568-577.

30. A. Laasraoui, J. Jonas. Prediction of Steel Flow Stresses at High Temperature and Strain Rates, Metall. Trans. A, 1991, 22, p 1545-1558.

31. A. Yoshie, H. Morikawa, Y. Onoe, K. Itoh. Formulation of static recrystallization of austenite in hot rolling process of steel plate, Trans. ISIJ, 1987, 27, p 425-431.

32. Y. G. Liu, M. Q. Li, J. Luo. The modeling of dynamic recrystallization in the isothermal compression of 300M steel, Mater. Sci. Eng. A 574 2013, 1-8.

33. W.Q. Li, Q.X. Ma. Constitutive modeling for investigating the effects of friction on rheological behavior during hot deformation, Mater. Des., 2016, 97, p 64-72.

34. E. I. Poliak, J. J. Jonas. A one-parameter approach to determining the critical conditions for the initiation of dynamic recrystallization, Acta. Mater., 1996, 44, p 127-136.

35. D. Trimble, G.E. O'Donnell. Constitutive Modelling for elevated temperature 
flow behaviour of AA7075, Mater. Des., 2015, 76, p 150-168.

36. Y. C. Lin, X. M. Chen, D. X. Wen, M. S. Chen. A physically-based constitutive model for a typical nickel-based superalloy, Comput. Mater. Sci., 2014, 83, p 282-289.

37. D. Q. Dong, F. Chen, Z. S. Cui. A physically-based constitutive model for SA508-III steel: Modeling and experimental verification, Mater. Sci. Eng. A, 2015, 607, p 630-639.

38. M. H. Wang, Y. F. Li, W. H. Wang, J. Zhou, A. Chiba. Quantitative Analysis of Work Hardening and Dynamic Softening Behavior of low carbon alloy Steel Based on the Flow Stress, Mater. Des., 2013, 45, p 384-392.

39. J. Wang, H. Xiao, H. B. Xie, X. M. Xu, Y. N. Gao. Study on hot deformation behavior of carbon structural steel with flow stress, Mater. Sci. Eng. A, 2012, 539, p 294-300.

40. G. L. Ji, F. G. Li, Q. H. Li, H. Q. Li, Z. Li. Research on the dynamic recrystallization kinetics of Aermet100 steel, Mater. Sci. Eng. A, 2010, 527, p $2350-2355$. 


\section{Figure Captions}
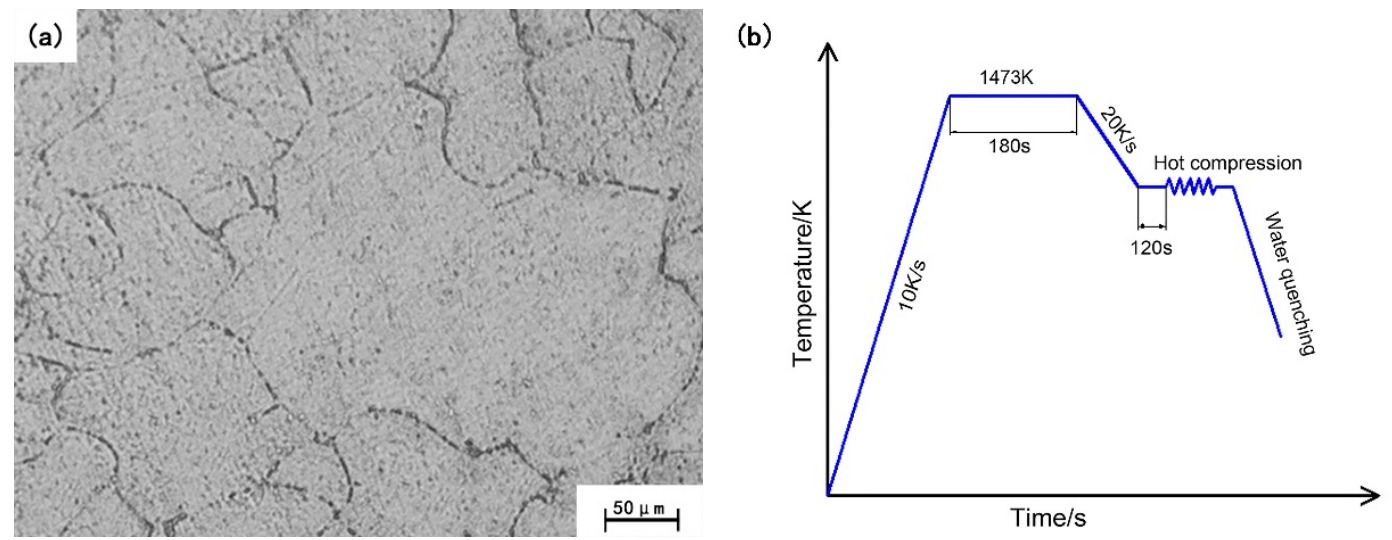

Fig. 1. (a) Original microstructure and (b) Scheme of thermal history for hot compression tests of $2 \mathrm{Cr} 11 \mathrm{Mo} 1 \mathrm{VNbN}$ martensitic stainless steel
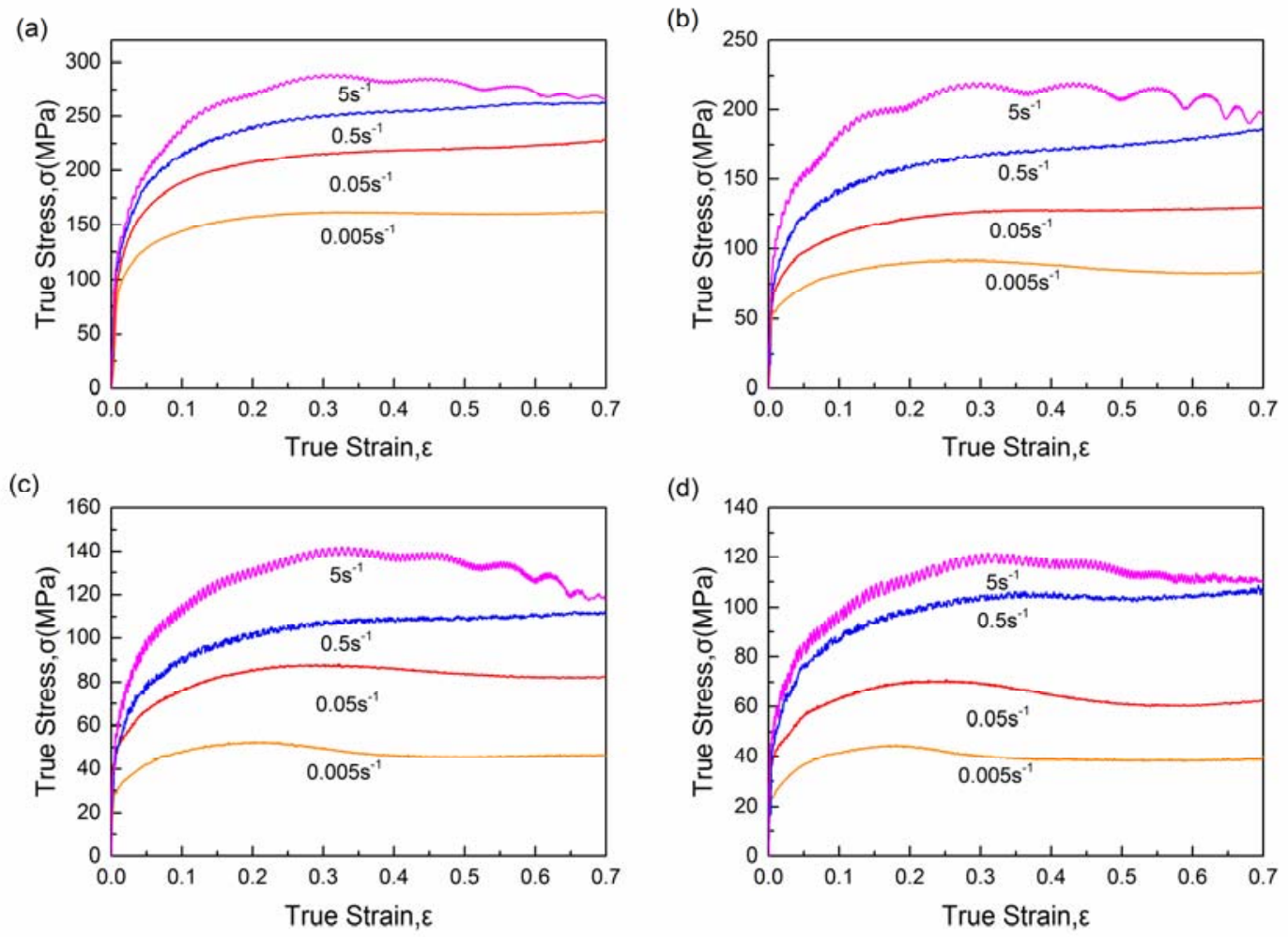

Fig. 2. True strain-stress curves at different strain rates and temperatures (a) $1173 \mathrm{~K}$, $0.005-5 \mathrm{~s}^{-1}$, (b) $1273 \mathrm{~K}, 0.005-5 \mathrm{~s}^{-1}$, (c) $1374 \mathrm{~K}, 0.005-5 \mathrm{~s}^{-1}$, (d) $1423 \mathrm{~K}, 0.005-5 \mathrm{~s}^{-1}$. 

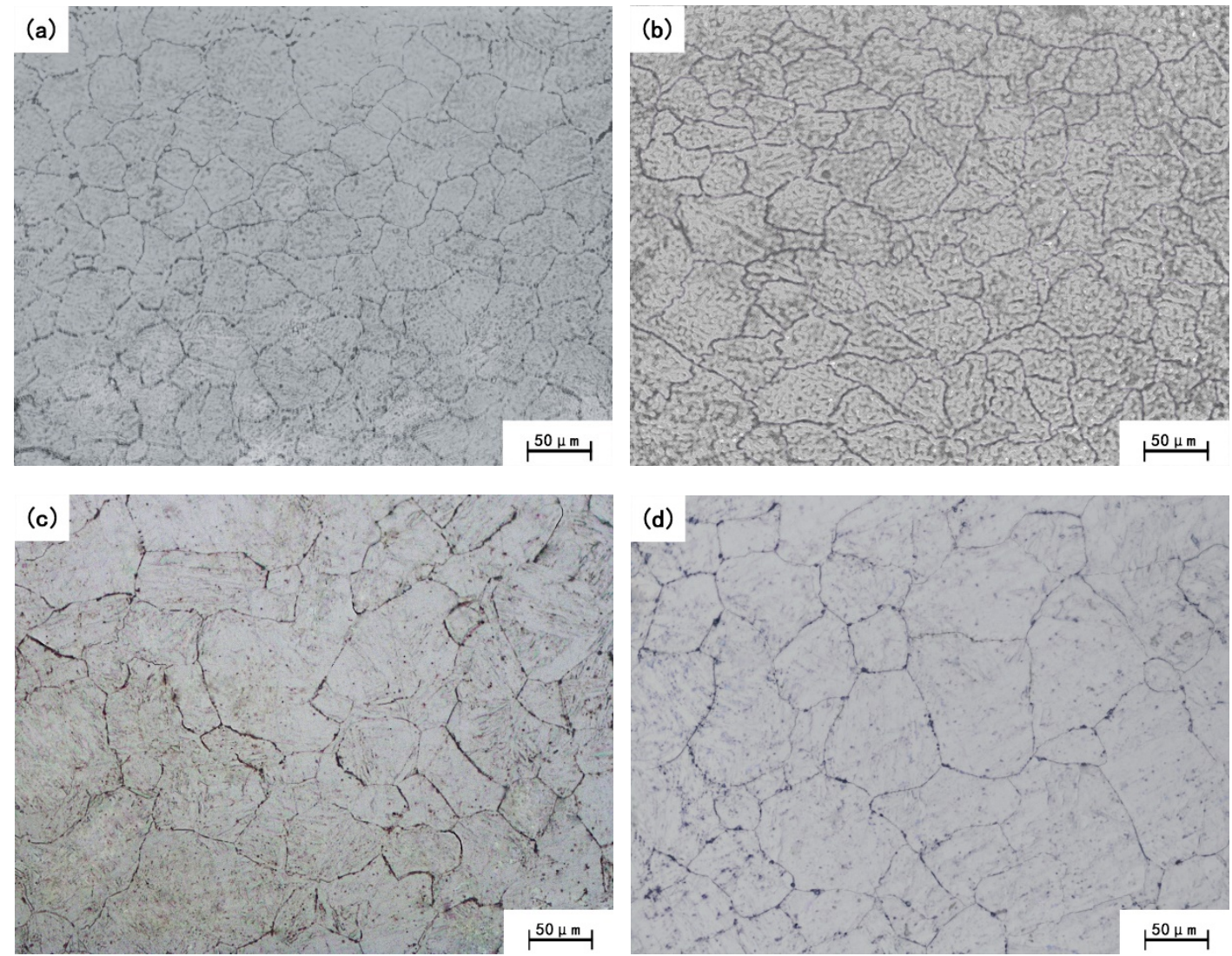

Fig. 3. Microstructure of steel at (a) temperature of $1273 \mathrm{~K}$, strain rate of $0.05 \mathrm{~s}^{-1}$ and strain of 0.7 (b) temperature of $1373 \mathrm{~K}$, strain rate of $0.05 \mathrm{~s}^{-1}$ and strain of 0.7 (c) temperature of $1423 \mathrm{~K}$ strain rates of $0.5 \mathrm{~s}^{-1}$ and strain of 0.7 (d) temperature of $1423 \mathrm{~K}$ strain rates of $5 \mathrm{~s}^{-1}$ and strain of 0.7

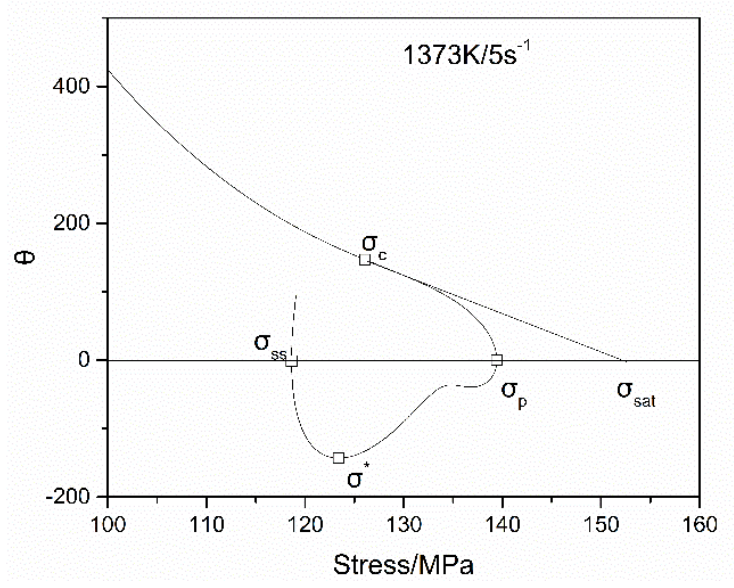

Fig. 4. Work hardening rate vs. stress at temperature of $1373 \mathrm{~K}$ and strain rate of $5 \mathrm{~s}^{-1}$. 
(a)

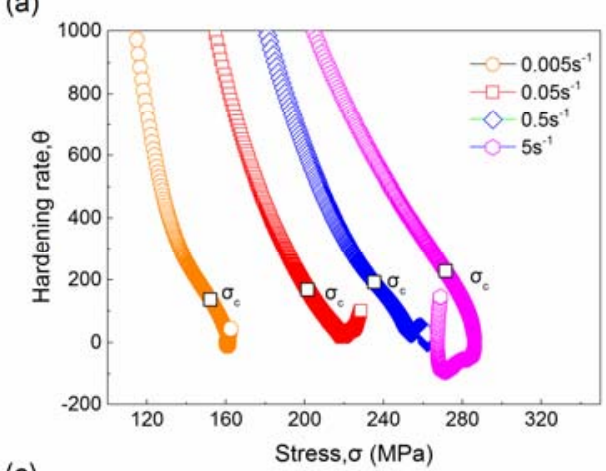

(c)

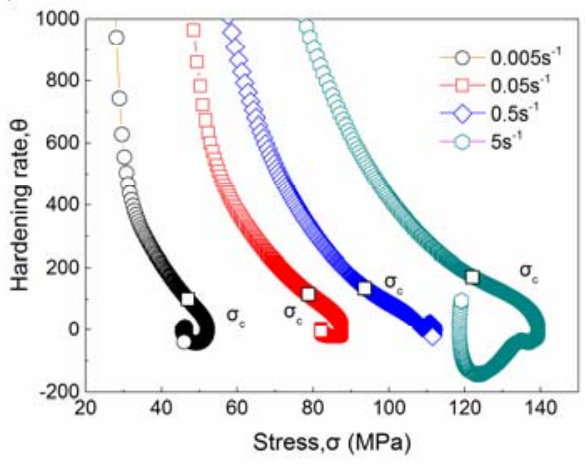

(b)

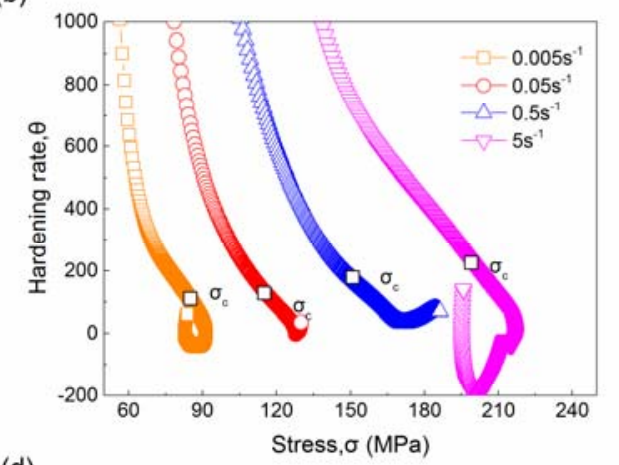

(d)

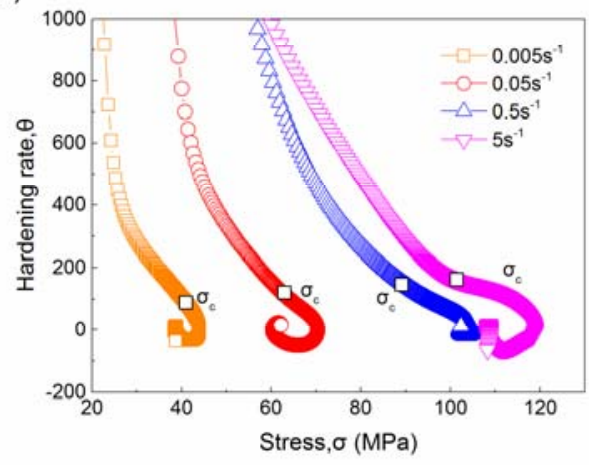

Fig. 5. Relationships between $\theta$ and $\sigma$ under different temperatures and strain rates (a-d) $1173 \mathrm{~K}, 1273 \mathrm{~K}, 1373 \mathrm{~K}, 1423 \mathrm{~K}$.

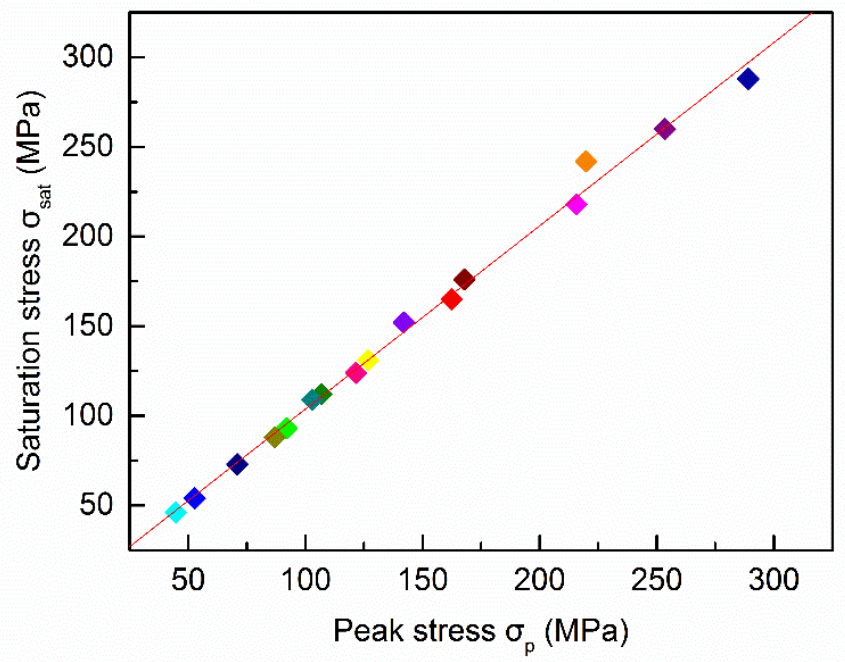

Fig. 6. Relationship between saturation stress $\sigma_{\text {sat }}$ and peak stress $\sigma_{\mathrm{p}}$ 


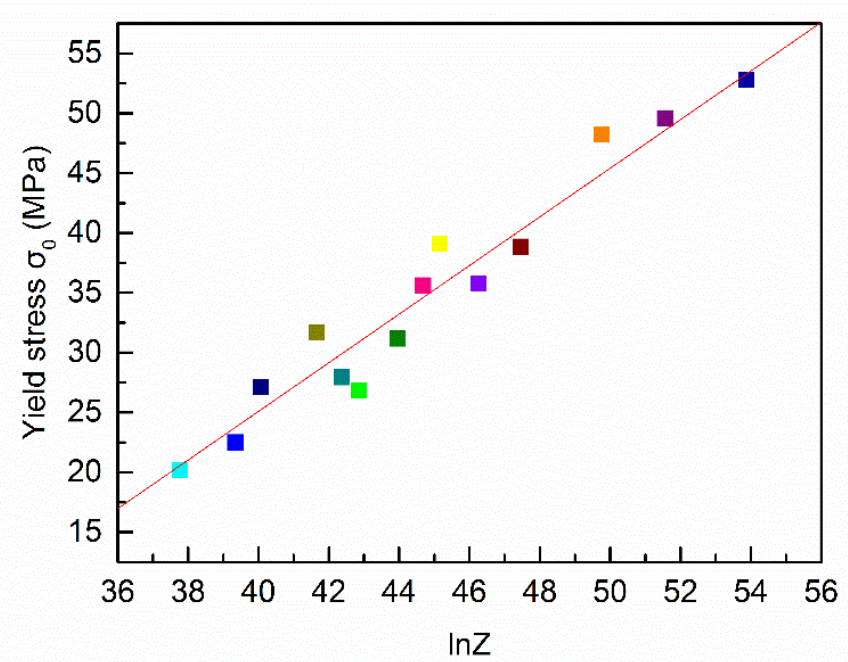

Fig. 7. Relationship between yield stress $\sigma_{0}$ and Zener-Hollomon parameter Z.

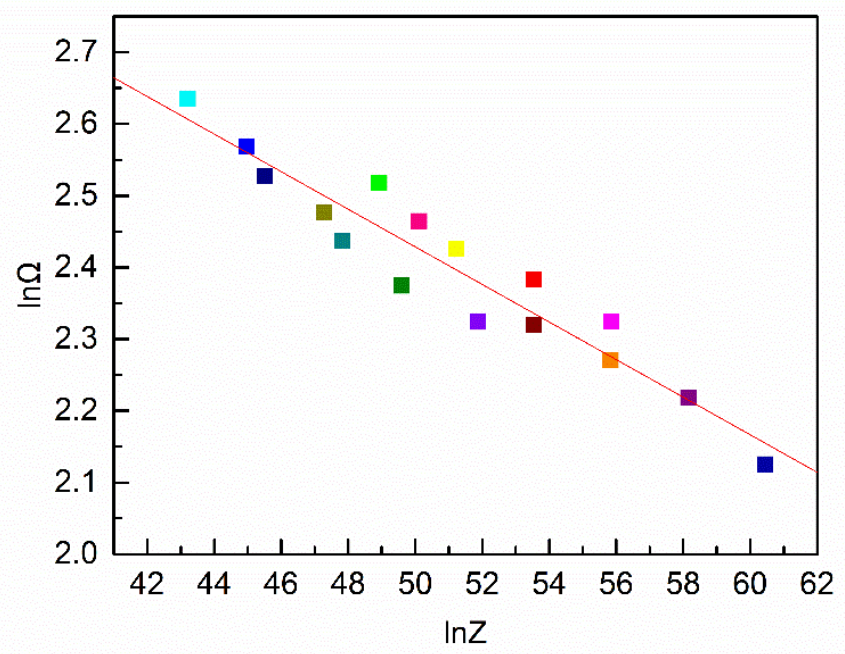

Fig. 8 Relationship between coefficient $\Omega$ and Zener-Hollomon parameter Z.

(a)

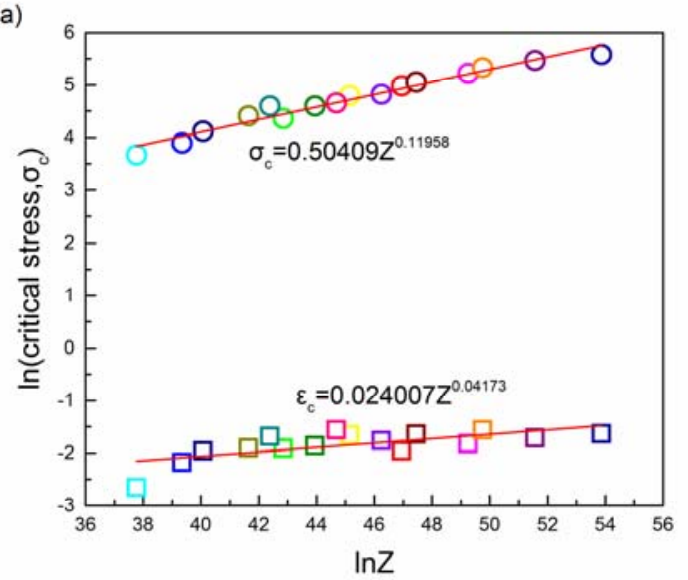

(b)

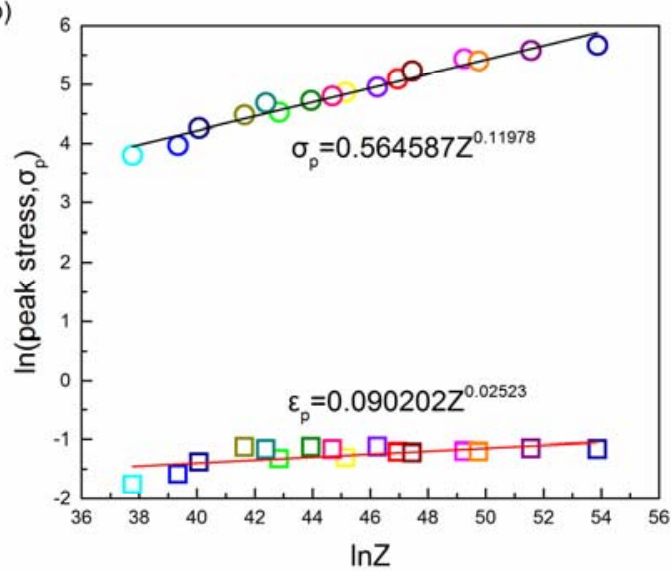


Fig. 9. Relationship between (a) parameter Z/A and $\sigma_{c}$, $\varepsilon_{\mathrm{c}}$. (b) parameter Z/A and $\sigma_{\mathrm{p}}$ $\varepsilon_{\mathrm{p}}$

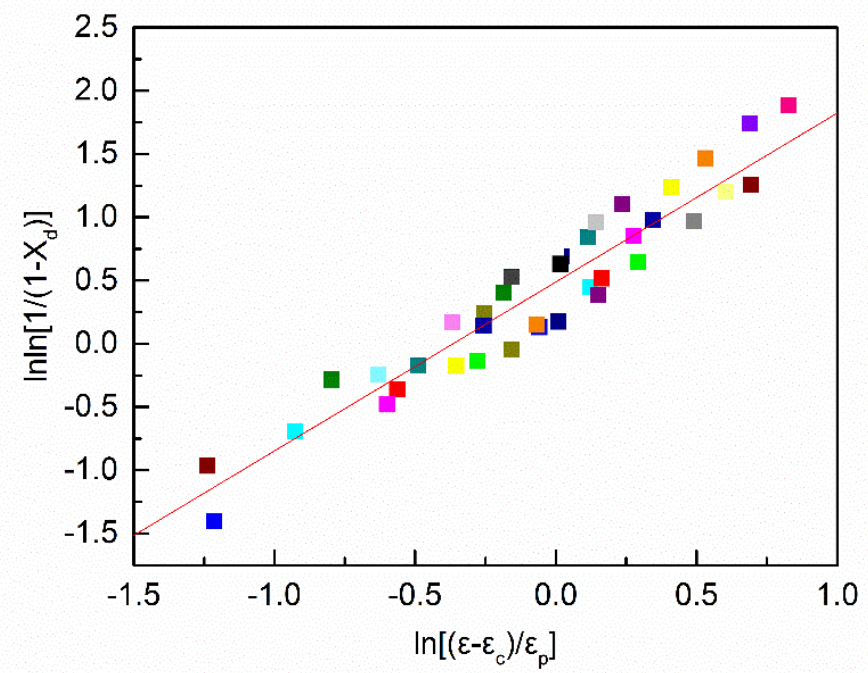

Fig. 10. Relationship between $\ln \ln \left(1 /\left(1-\mathrm{X}_{\mathrm{d}}\right)\right)$ and $\ln \left[\left(\varepsilon-\varepsilon_{\mathrm{c}}\right) / \varepsilon_{\mathrm{p}}\right]$.

(a)

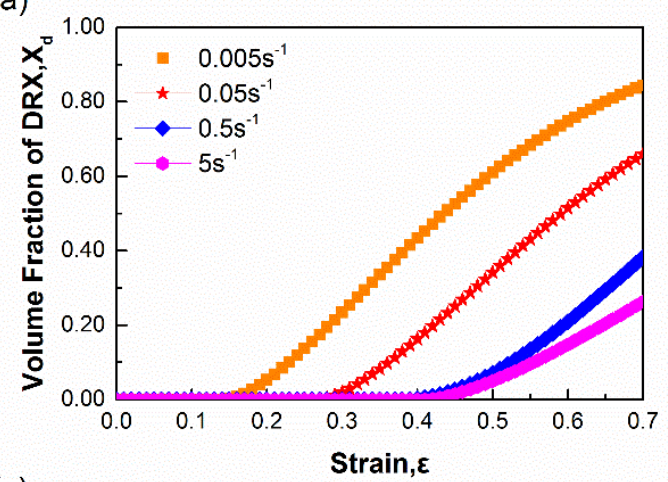

(c)

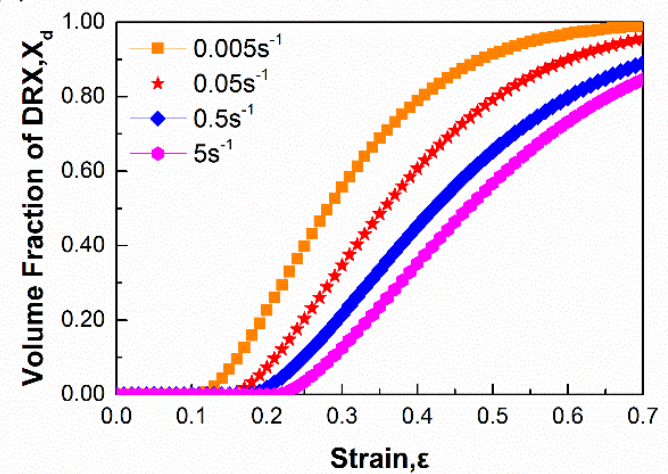

(b)

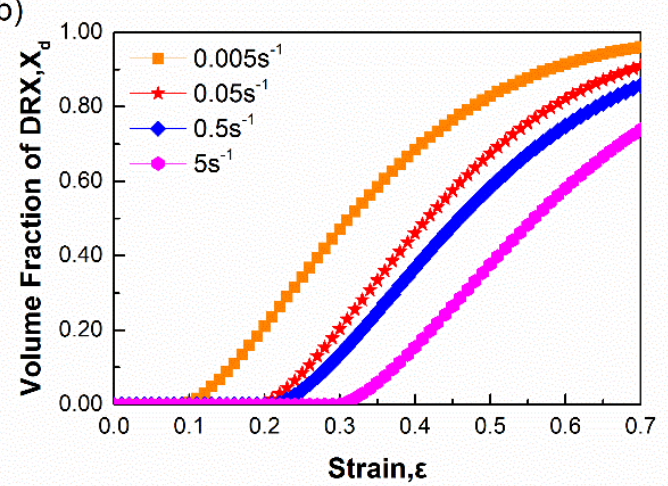

(d)

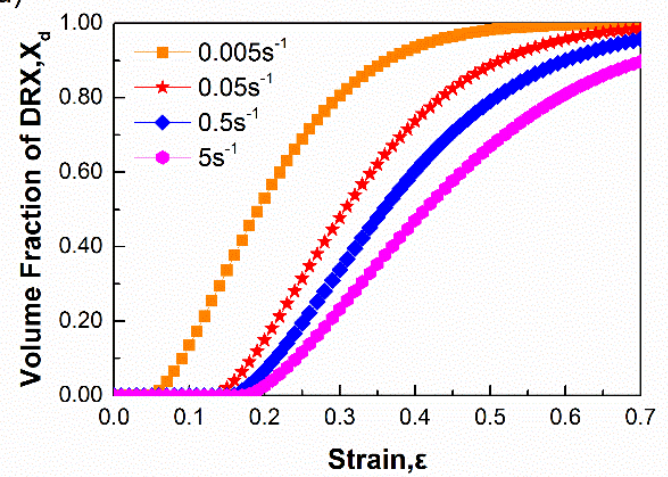

Fig. 11. Prediction of volume fraction of DRX under various deformation condition with temperature of (a) $1173 \mathrm{~K}$, (b) $1273 \mathrm{~K}$, (c) $1373 \mathrm{~K}$, (d) $1423 \mathrm{~K}$. 


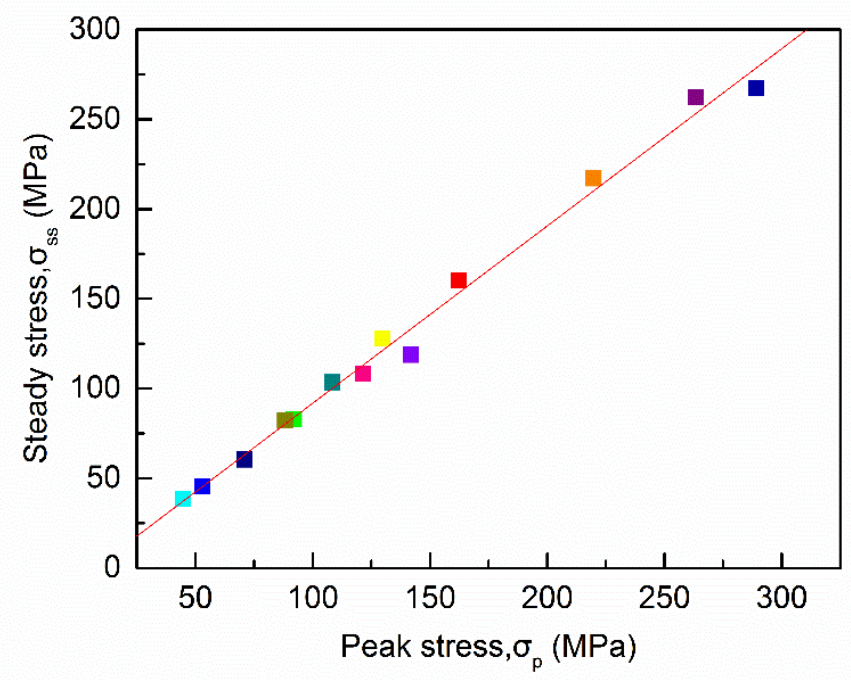

Fig. 12. Relationship between steady stress $\sigma_{\mathrm{ss}}$ and peak stress $\sigma_{\mathrm{p}}$.

(a)

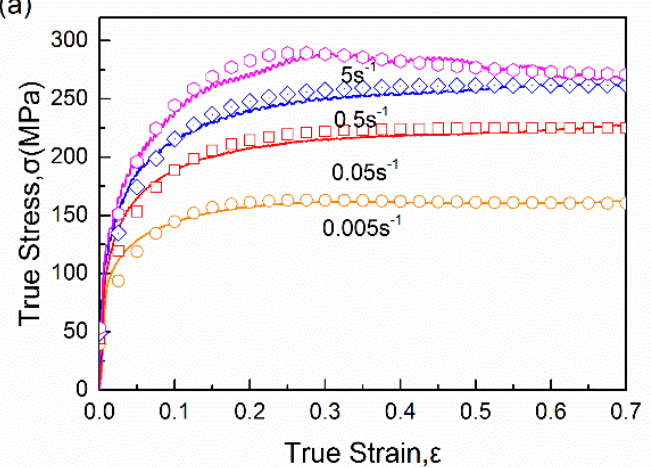

(c)

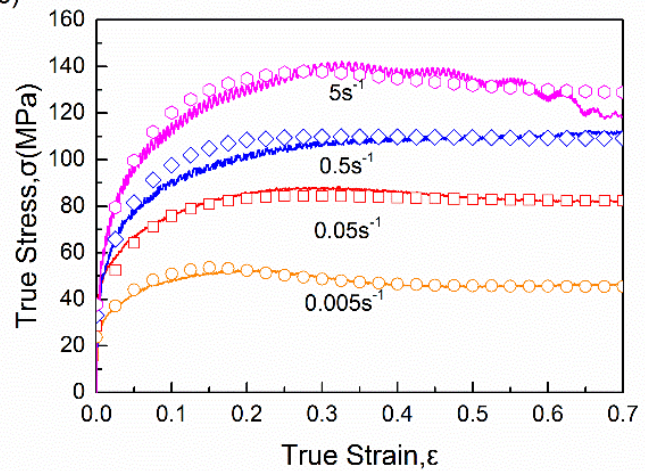

(b)

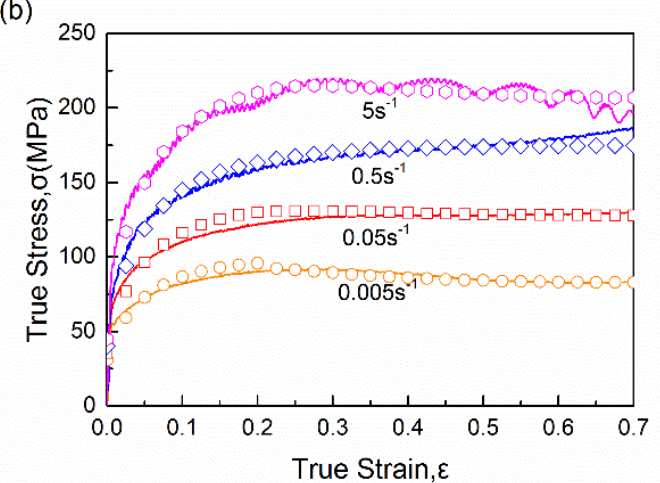

(d)

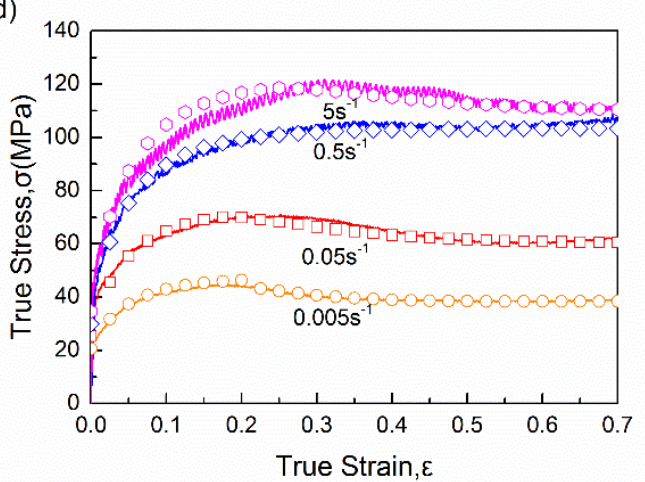

Fig. 13. Comparison experimental and predicted flow stress value of studied steel under various hot deformation conditions. 


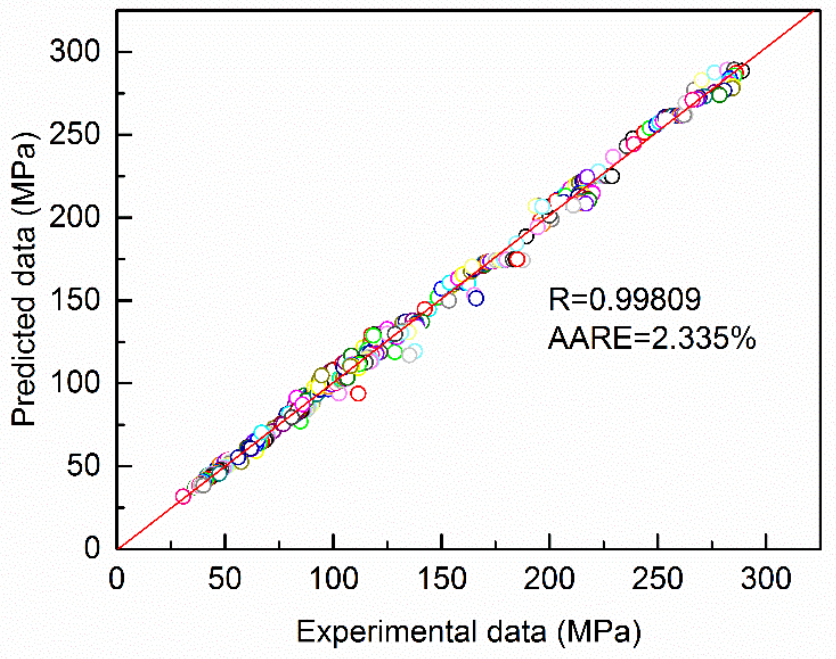

Fig. 14. Correlation between the experimental and predicted flow stresses during hot deformation. 